ISSN 1112-9867

http://www.jfas.info

\title{
NUMERICAL ASSESSMENT OF CONVENTIONAL REGULATION EFFECTIVENESS FOR SMOKE REMOVAL FROM A TWO LEVEL UNDERGROUND STATION
}

\author{
B. Benkoussas ${ }^{1, *}$, R. Djedjig ${ }^{1}$ and O. Vauquelin ${ }^{2}$ \\ ${ }^{1}$ École Nationale Polytechnique, Département de Génie Mécanique, \\ 10 Rue des frères Oudak, Hassen Badi, El-Harrach, 16200, BP 182, Alger, Algérie \\ ${ }^{2}$ Aix-Marseille Université, Laboratoire IUSTI/ UMR CNRS 7343, 5 rue E. Fermi, 13453 Marseille \\ Cedex 13, France
}

Received: 25 Jaunary 2016 / Accepted: 06 April 2016 / Published online: 01 May 2016

\begin{abstract}
The effectiveness of an underground smoke control system mainly depends on fire safety engineering that is provided, and which is generally established using smoke spread field and temperature distribution predictions. In the present study, smoke spread and temperature predictions are carried out for a typical two level underground station, under conventional smoke control regulation. The aim is to examine the effectiveness of the conventional regulation and, to look for better smoke control strategies which ensure safe evacuation operations. To this end, an in-depth investigation is carried out on selected ventilation strategies. The calculations are made using FDS code. Results highlight the ineffectiveness of the conventional regulation for some zones of the station and showed irrefutable positive impact of blowing with a moderate flow rate, and the implementation in the vicinity of the stairways of smoke barriers, when smoke control strategy through tunnels is performed.
\end{abstract}

Keywords: underground station; conventional regulation; ventilation strategies; smoke temperature; smoke barriers.

Author Correspondence, e-mail: bouzid.benkoussas@enp.edu.dz ; bbenkoussas@yahoo.fr doi: http://dx.doi.org/10.4314/jfas.v8i2.16 


\section{INTRODUCTION}

In order to solve the problem of urban transport in large cities, Algeria has achieved in recent years substantial underground transport infrastructure such as Algiers Metro. The major risk associated with these facilities is fire and the containment of smoke produced.The various fires which occurred in underground facilities over the world have caused severe damages and killed hundreds of people $[1,2]$. It is often reported that for semi-confined fires, as for underground stations, the majority of victims are suffocated by toxic and hot fumes. Intuitively, ventilation is the first practice which is applied to secure the space and users. However, this must be performed under appropriate conditions; otherwise, it may not be effective.

Underground ventilation system design can be developed from the predictions of smoke spread field, temperature distribution and air-smoke mixtures velocity [3]. These parameters are relevant factors in establishing fire security strategies that are able to avert large number of victims.

In last decades, a number of numerical and experimental studies on various aspects of smoke ventilation were carried out in reduced and full scale underground facilities [4, 5, 6, 7, and 8]. Tsukahara et al. [9] reported that the major problem in smoke control system design is that smoke flow and evacuation routes directions coincide. They evaluated evacuation routes for large-scale subway fire, to design pathways without smoke interference. Their conclusion is that, downward evacuation can be more effective than the upward one. However, the feasibility of such proposal on the existing subway stations is questionable. It should be noted that new arrangements, aiming at ensuring safe pathways, are often difficult to implement in existing underground stations.

Following conclusions and suggestions from the literature, safety regulation in establishments receiving public (ERP) such as underground stations was developed [10]. Applied rules in case of fire are intended to either quickly evacuate the public outside or to ensure the safekeeping of users. Smoke control should have as targets the extraction of part of the smoke and gases to: (a) make practicable pathways for public evacuation and emergency services, (b) limit fire and smoke spread by removing heat and unburned gas outwards. The multi-level 
underground stations are almost closed to ambient surroundings, so that smoke extraction must be exclusively mechanical and carried out by zones defined on case by case basis. For each zone the minimum rate of air renewal must be 15 volumes per hour. The volume of air must be enough for eliminating any smoke and avoiding an explosive atmosphere [11]. In addition, each zone should be equipped with a set of independent high flow rate fans (HFR)F for extraction of smoke and blowing of air. In the event of a disaster, burned levels are put in depression and others in overpressure.

In the same context, this work aims firstly, at investigating the effectiveness of conventional regulation applied to Establishments Receiving Public (ERP), by simulating a fire scenario in a two level subway station, followed secondly by an in-depth assessment of smoke control ventilation modes.

\section{NUMERICALAPPROACH}

Experiments on real scale fire in underground stations are very costly and difficult to carry out. Therefore, few experimental results are presented in the literature. The vast majority of the work was performed numerically. One of the most frequently used codes is Fire dynamics Simulator (FDS) [12, 13]. It is a computational fluid dynamics model of fire-driven fluid flow. It solves numerically a form of the Navier-Stokes equations appropriate to low-speed, thermally-driven flow, with an emphasis on smoke and heat transport from fires. It uses a mixture fraction combustion model which assumes that combustion is mixing-controlled, and that the reaction of fuel and oxygen is infinitely fast. Turbulence is treated using Large Eddy Simulation model. SmokeView is a visualization program that is used to display the FDS simulation results. The results from the literature have shown that FDS with its existing features can deliver accurate predictions for most important parameters that are of significance in the fire safety context, $[14,15,16,17$, and 18].

\section{PHYSICAL MODEL}

\subsection{Geometry}

The typical subway station under investigation is shown in (Fig. 1). It has two levels, the 
platforms at the lower level and the mezzanine at the upper level. They are connected in space through four stairways of $5 \mathrm{~m}$ length and $1.5 \mathrm{~m}$ width each. The station is $70 \mathrm{~m}$ length and $14 \mathrm{~m}$ width. The mezzanine is $50 \mathrm{~m}$ x $14 \mathrm{~m} \mathrm{x} 4.5 \mathrm{~m}$. The exit door of the station, located at the mezzanine, is rectangular in shape of $24.45 \mathrm{~m}^{2}(6 \mathrm{~m} \mathrm{x} 4.075 \mathrm{~m})$. Each platform is $70 \mathrm{~m}$ length, $4 \mathrm{~m}$ height, and $4 \mathrm{~m}$ width. The tunnels on each side of the station have cross-section area of $33.75 \mathrm{~m}^{2}(7.5 \mathrm{~m} \times 4.5 \mathrm{~m})$. On the right side platform, a 4 carriages train of $16 \mathrm{~m}$ length each is parked. The carriages are $2.75 \mathrm{~m}$ width and $2.5 \mathrm{~m}$ height above the platform floor. Each carriage has three doors on each side. The station is equipped with two mechanical exhaust systems: (1) two Lower Floor Fans (LFF), located in the midline along the lower level of the station at the ceiling on each side, to extract air and smoke outside the platforms, (2) two Upper Floor Fans (UFF), set up on the mezzanine ceiling, in the midline $27.5 \mathrm{~m}$ from each end, to suck air-smoke mixture outside. The fans are mounted on vents $5 \mathrm{~m}^{2}$ each, $(2.5 \mathrm{m \times} 2 \mathrm{~m})$. Additional characteristic details of the station are shown in (Fig. 1).

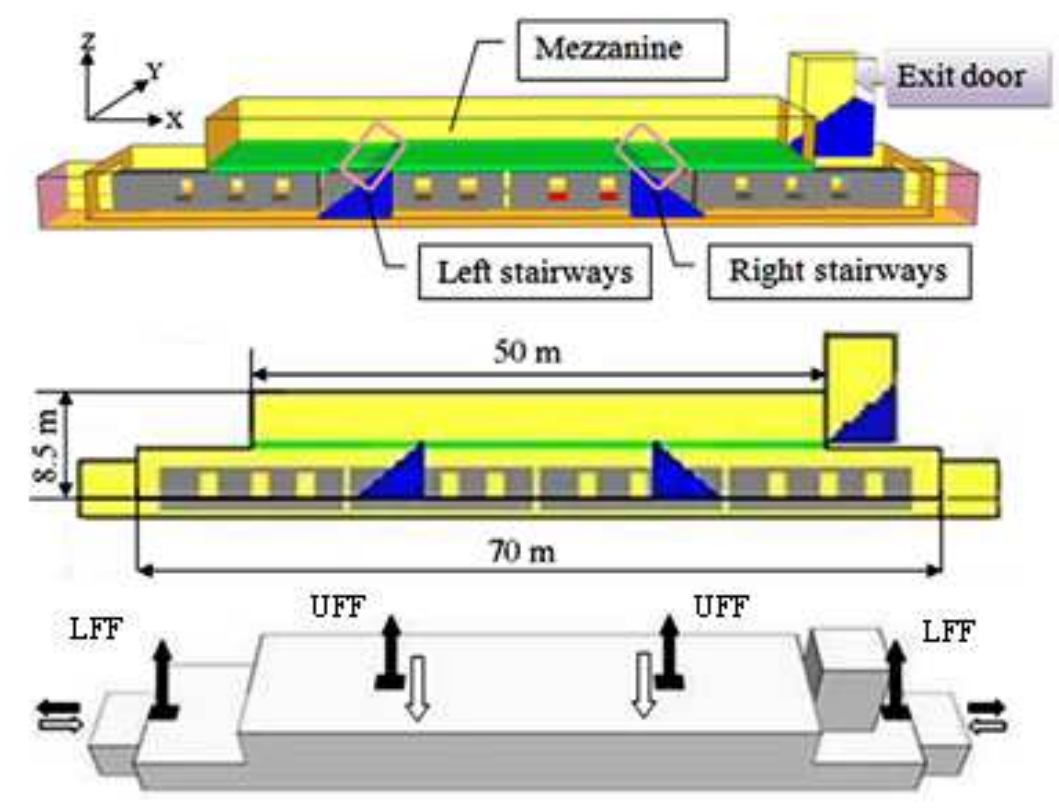

Fig.1. Schematic drawing of the station

\subsection{Assumptions and general considerations}

In this study, we focus on the transport of hot smoke gases generated by a fire which occurs in one of the four train carriages. For the design of a ventilation system, for which the worst case 
situation will be that of the fully developed fire, steady simulations were performed using a constant convective heat release rate of $15 \mathrm{MW}$, uniformly distributed on the inner surface of the carriage on fire. Radiation heat losses are quite high, mainly in the vicinity of the source and in early stage of the fire. In this study, radiation heat losses are neglected. Fan extractors (LFF) of the platform level operate at full power with $50 \mathrm{~m}^{3} / \mathrm{s}$ flow rate each. Rectangular mesh discretization of the physical domain is implemented.

CFD numerical simulations require hours or even days to run on the latest personal computers. One of the most significant factors influencing the computation time is the size of the computational grid specified. FDS simulations for selected grid sizes were performed in preliminary work to highlight the effect of grid size on the estimate of the temperature. In the vicinity and the centerline of the fire, temperature is higher when the grid sizes are fine. To validate the adopted grid size relative to the fire area, the plume centerline temperature is determined using the well established Heskestad's empirical correlation and compared to FDS predicted temperature $[12,13]$. As we focus on the temperature distribution along the platform and in the mezzanine, and due to a large number of scenarios which can be scheduled, we opted for a mesh size that predicts maximum temperature close to that obtained empirically with moderate computing time. The Heskestad correlation provides an estimate that is closer to that obtained numerically for the grid size of $0.25 \mathrm{~m} \times 0.25 \mathrm{~m} \times 0.25 \mathrm{~m}$. The domain is divided thus, into $(0.25 \times 0.25 \times 0.25) \mathrm{m}^{3}$ cubes giving 521,564 cells. On the exit door, a condition type OPEN (atmospheric pressure) is imposed. On tunnels and vents of the mezzanine and platform level, flow rates are selected, depending on the ventilation strategy considered. The scenario where the fire is located in the 3rd carriage (almost between the stairways) is used for this investigation. This case is the most critical and can lead to unpredictable smoke flows. Indeed, evacuation pathways that are a priori the stairways alone, may be quickly trapped by hot gases. Several air blowing and smoke removal scenarios through the tunnels are tested to determine the most optimal strategy. The selected strategies are defined relatively to the flow rate through tunnels. These can be air blowing or smoke extraction through both tunnels strategies, and air blowing through one tunnel and smoke extraction through the other tunnel strategy (anti-symmetric strategy). The control of the 
imposed flow rates, particularly through tunnels, aims to preserve from smoke the communication pathways between both levels and the mezzanine.

The main variable used for analysis is temperature. At the platforms, 13 measurement points spaced $5 \mathrm{~m}$ were placed in the middle along each platform, $1.5 \mathrm{~m}$ height above the ground. In the mezzanine, 25 measurement points are distributed on a horizontal cross-section $1.5 \mathrm{~m}$ height above the ground. The positions of these points are chosen symmetrically pairwise with respect to the width of the mezzanine. The number of measurement points is higher on the left of the mezzanine, near the exit door of the station (Fig. 2). Such a selection is based upon the natural paths that evacuees take when they ascend the stairways and head towards the exit. These measurements points are relevant with regards to safety.

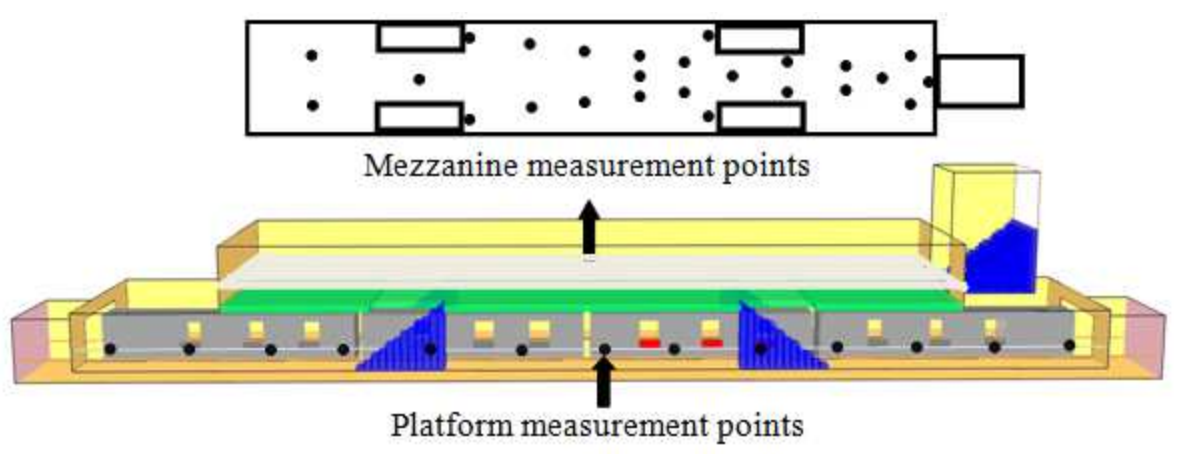

Fig.2. Location of measurement points throughout the levels of the station

\section{RESULTS AND DISCUSSION}

\subsection{Test result for conventional ventilation regulation}

To test the effectiveness of the requirements of existing regulation, blowing into the mezzanine through the vents placed in the ceiling is implemented. The selected rate of 14 $\mathrm{m}^{3} / \mathrm{s}$ blowing air into the mezzanine, through the two vents results in a total blowing of $50,400 \mathrm{~m}^{3}$ per hour. This is slightly higher than that prescribed by the existing regulation which is 15 volumes per hour. The fire is supposed to take place in the third carriage. Extraction through each vent of the platforms level is maintained constant at $50 \mathrm{~m}^{3} / \mathrm{s}$. The boundary condition OPEN is imposed on tunnels and exit door (Fig. 3). 


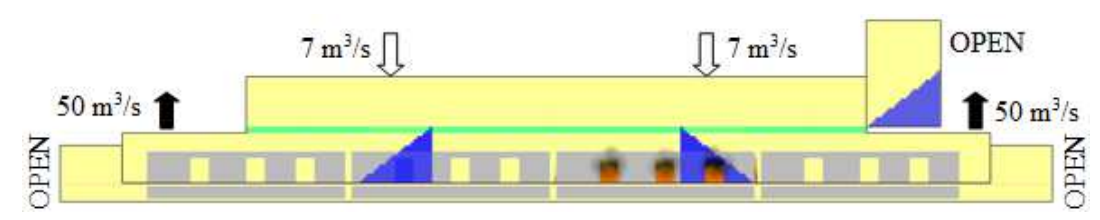

Fig.3. Boundary conditions (effectiveness of conventional regulation)

Results of smoke spread for selected simulation times are illustrated in (Fig. 4). They clearly show that blowing in the upper level (mezzanine) with an extraction in the lower level cannot prevent the rise of smoke. Indeed, the mezzanine is quickly invaded by toxic and opaque smoke and temperatures reached unsustainable levels (around $100{ }^{\circ} \mathrm{C}$ ) as shown in (Fig. 5a).
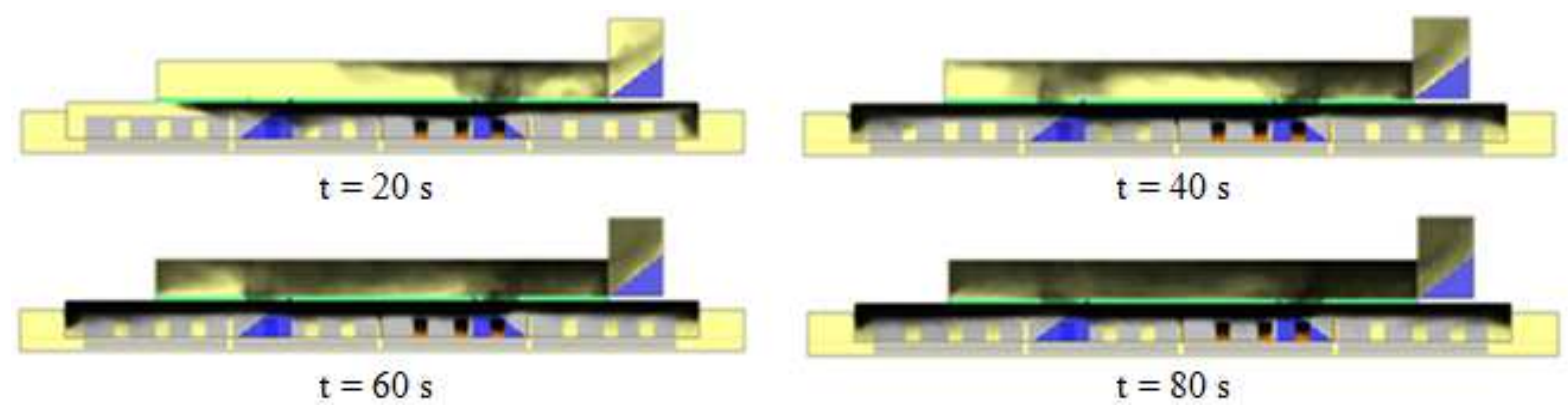

Fig.4. Station smoke behavior for conventional ventilation regulation

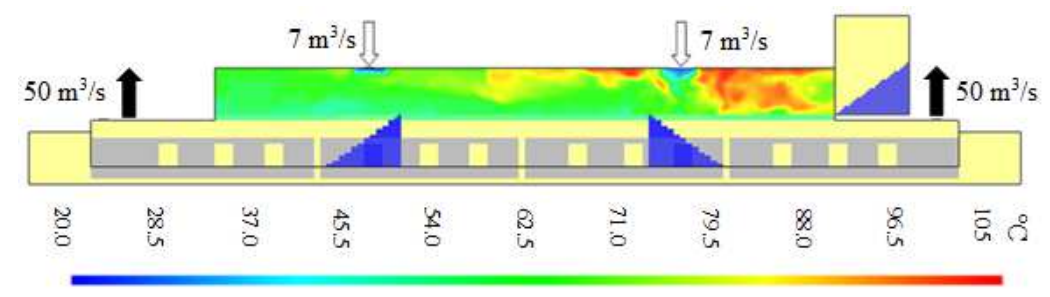

Fig.5a. Temperature field in the mezzanine at $t=60 \mathrm{~s}$

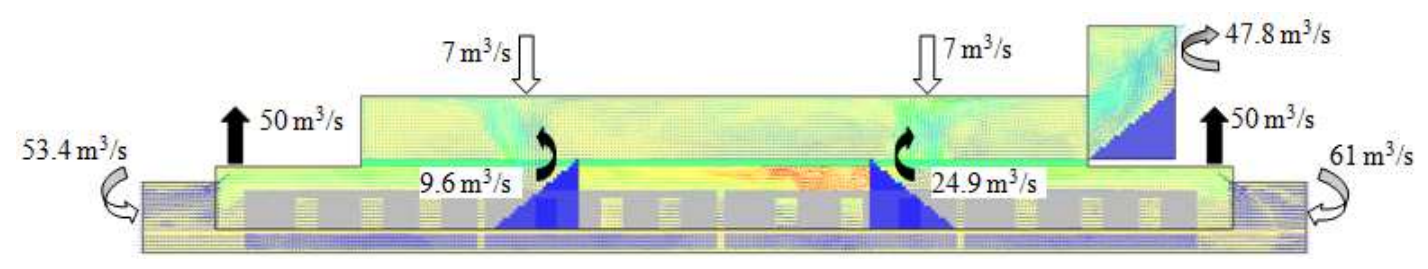

Fig.5b. Flow rates set in motion in the station for conventional test case at $t=60 \mathrm{~s}$

Flow rates set in motion in the station for conventional test case at $t=60 \mathrm{~s}$ are illustrated in (Fig. 5b). The airflow rates through the openings of the station are determined. It can be observed that substantial amounts of air are sucked through tunnels. These are almost immediately extracted through platforms vents. It is worth noting that extractions through 
platforms vents are not acting on the smoke produced but on tunnels induced air. Consequently smoke finds its way to the upper level through stairways. The pressure generated by the fans within the mezzanine vents, at the ceiling opposite the stairways, acts downwards on the ascending smoke. The buoyancy force and the pressure of the jet fans spread the smoke on either side of the mezzanine and towards the exit of the station.

The results presented in (Figs. 4, 5a, and 5b) demonstrate that the strategy applied does not have the effectiveness expected. Hence, the need to look for optimal ventilation strategies that would ensure the safety becomes crucial. Three distinct ventilation strategies are proposed and examined: (a) strategy with blowing through tunnels, (b) strategy with extraction through tunnels, (c) strategy with blowing through one tunnel while extracting through the other tunnel. Note that, selected flow rates are specified on tunnels, depending on the ventilation strategy considered. Extraction is maintained constant at $50 \mathrm{~m}^{3} / \mathrm{s}$ flow rate per vent at the platforms level, and the boundary condition OPEN is imposed on exit door. In the following sections, analysis of relevant trends related to strategies investigated are illustrated and discussed.

\subsection{Strategy one: blowing through tunnels}

In this configuration, equal airflow rate through tunnels is performed mechanically. The flow

rates $17 \mathrm{~m}^{3} / \mathrm{s}, 34 \mathrm{~m}^{3} / \mathrm{s}, 51 \mathrm{~m}^{3} / \mathrm{s}$, and $68 \mathrm{~m}^{3} / \mathrm{s}$ are considered. Note that $34 \mathrm{~m}^{3} / \mathrm{s}$ corresponds approximately to a velocity of $1 \mathrm{~m} / \mathrm{s}$ at the tunnel inlet section. The compiled results are for $20 \mathrm{~m}^{3} / \mathrm{s}$ extraction flow rate through each vent of the mezzanine, for two selected times $50 \mathrm{~s}$, and $120 \mathrm{~s}$. Note that at $\mathrm{t}=120 \mathrm{~s}$, steady state regime is reached and beyond this time, smoke behavior and gas temperature vary very slightly. 

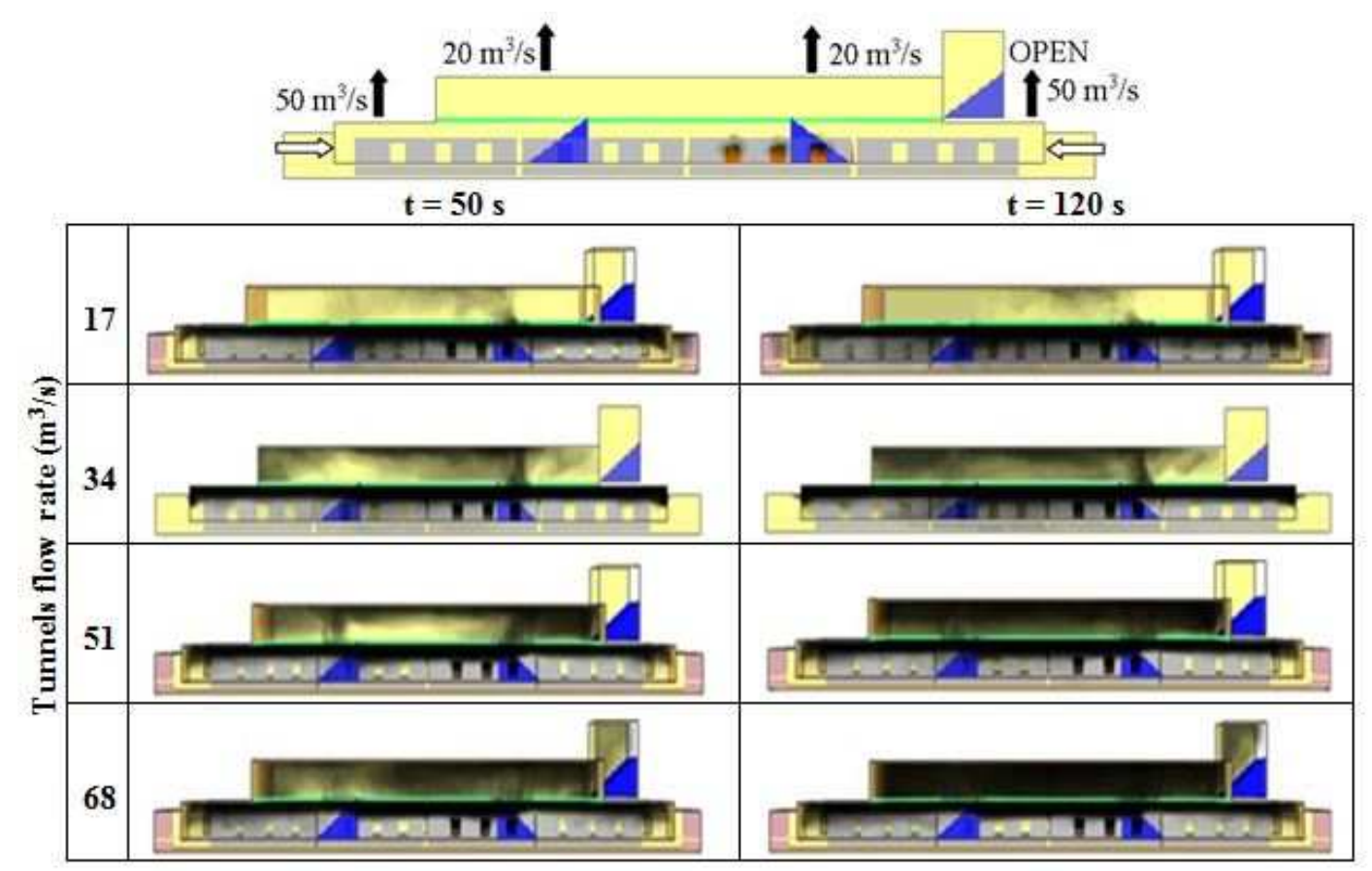

Fig.6. Smoke behavior in the mezzanine and the station (blowing through tunnels)

Figure 6 shows the results of smoke behavior in the station. The smoke makes its way to the mezzanine via the two right stairways, located in the vicinity of the smoke source, for low ventilation rates through tunnels, while for high flow rates this ascent is done through the four stairways. Smoke in the mezzanine is conveyed to the left side under the effect of the air stream coming from the exit door of the station located on the right side. It accumulates and quickly fills the volume of the mezzanine, especially at high tunnels flow rates. Particularly, for high flow blowing on tunnels $\left(68 \mathrm{~m}^{3} / \mathrm{s}\right)$, smoke manages to leave the station throughout upper part of the exit door as illustrated in (Fig. 7), through velocity profiles. It is also found that up to $51 \mathrm{~m}^{3} / \mathrm{s}$ tunnel flow rates, smoke is confined at the platforms level; smoke layers remain stuck to the ceiling and become thicker and thicker. This strategy may secure the lower level of the station only. 


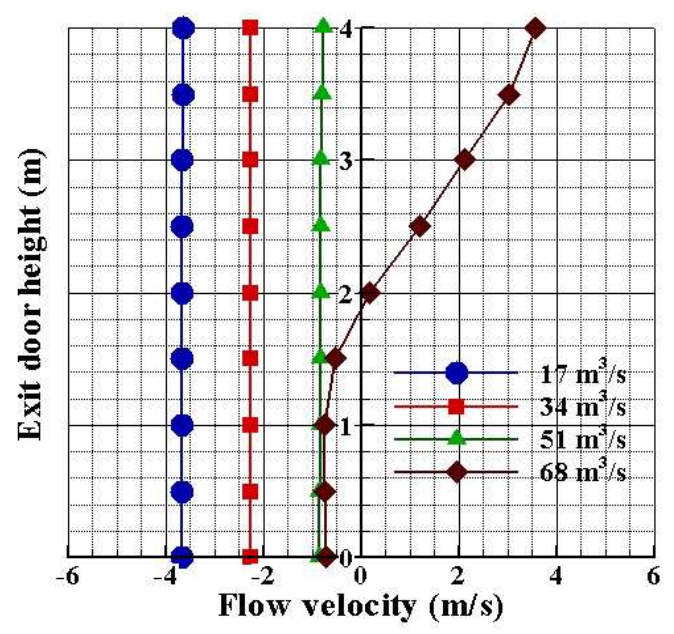

Fig.7. Exit door flow velocity profiles for different tunnel blowing flow rates

Figure 7 shows velocity profiles at the exit door of the station for various blowing flow rates. Results for tunnel blowing flow rates in the range of $17 \mathrm{~m}^{3} / \mathrm{s}$ to $51 \mathrm{~m}^{3} / \mathrm{s}$ indicate that air is sucked from outside over the whole height of the exit door (negative velocities). However, for $68 \mathrm{~m}^{3} / \mathrm{s}$, air is sucked in through the lower part of the exit door up to $2 \mathrm{~m}$ height (negative velocity) and smoke is exhausted through the upper part of the exit door (positive velocity). Table 1 presents platforms and mezzanine average temperature, maximum recorded temperature values at both levels, and the percentage of points registering temperatures over $40{ }^{\circ} \mathrm{C}$, for various tunnels blowing flow rates

Table 1. Platforms and mezzanine average and maximum temperatures

\begin{tabular}{|c|c|c|c|c|c|c|c|}
\hline \multirow{2}{*}{\multicolumn{2}{|c|}{ Flow rate $\left(\mathrm{m}^{3} / \mathrm{s}\right)$}} & \multicolumn{4}{|c|}{ Temperature $\left({ }^{\circ} \mathrm{C}\right)$} & \multirow{2}{*}{\multicolumn{2}{|c|}{$\begin{array}{l}\text { \% Excess } \\
\text { temperature }\end{array}$}} \\
\hline & & \multicolumn{2}{|c|}{ Average } & \multicolumn{2}{|c|}{ Maximum } & & \\
\hline Mezz. & Tunnels & Mezz. & Platf. & Mezz. & Platf. & $\%$ Mezz. & $\%$ Platf. \\
\hline & & & & & & $>40^{\circ} \mathrm{C}$ & $>40^{\circ} \mathrm{C}$ \\
\hline 20 & 17 & 23.40 & 54.01 & 36.18 & 77.77 & 0 & 88.74 \\
\hline 20 & 34 & 32.28 & 41.57 & 39.99 & 59.32 & 0 & 46.15 \\
\hline 20 & 51 & 50.05 & 34.12 & 78.01 & 57.10 & 96 & 11.54 \\
\hline 20 & 68 & 63.45 & 34.51 & 79.97 & 63.44 & 100 & 03.85 \\
\hline
\end{tabular}


From Table 1, we remark that platform security level is enhanced by blowing flow rate increase through tunnels; the opposite occurs for the mezzanine. Indeed, the average temperature increases in the mezzanine and decreases in the platform. The number of measurement points that exceeds $40^{\circ} \mathrm{C}$ varies in the same trend, with $0 \%$ in the mezzanine for $17 \mathrm{~m}^{3} / \mathrm{s}$ flow rate and $100 \%$ for $68 \mathrm{~m}^{3} / \mathrm{s}$ flow rate. At the platforms, an opposite tendency is observed: around $4 \%$ of measurement points exceed $40^{\circ} \mathrm{C}$ for high blowing rate, whereas, more than $88 \%$ of temperature measurements are over $40^{\circ} \mathrm{C}$ for low flow rate.

Temperature fields shown in (Figures $8(\mathrm{a}, \mathrm{b})$ ) at the horizontal cross-section $1.5 \mathrm{~m}$ height above the ground in both levels illustrate the effect of blowing flow rate increase. It can be seen that areas where temperature is high in the mezzanine, are in the vicinity of the stairways (Fig. 8a). At platforms level, maximum temperature is near the carriage on fire (Fig. 8b). Note that temperature fields in the mezzanine and within platforms levels are truncated to areas where temperature exceeds $40{ }^{\circ} \mathrm{C}$. It can be concluded that non-colored areas are secure areas.

(a) Mezzanine

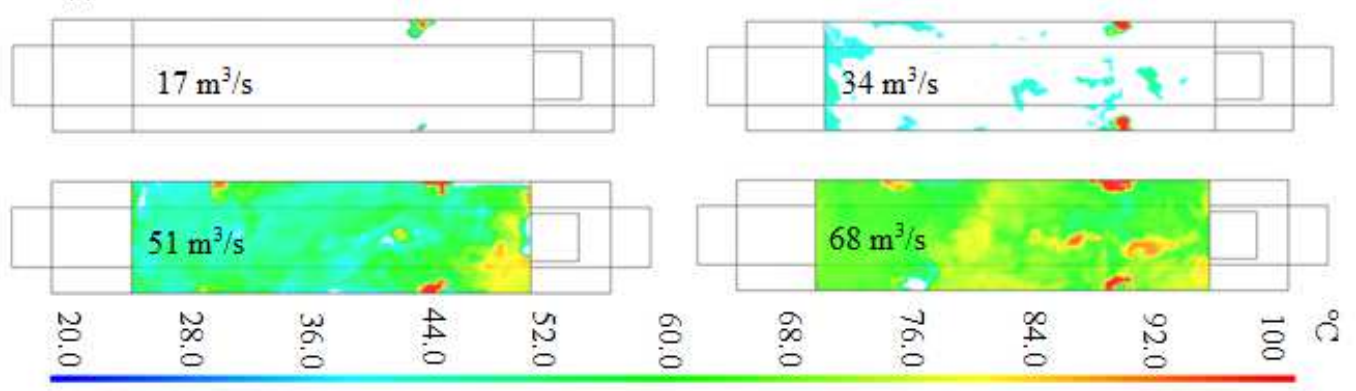

(b) Platforms

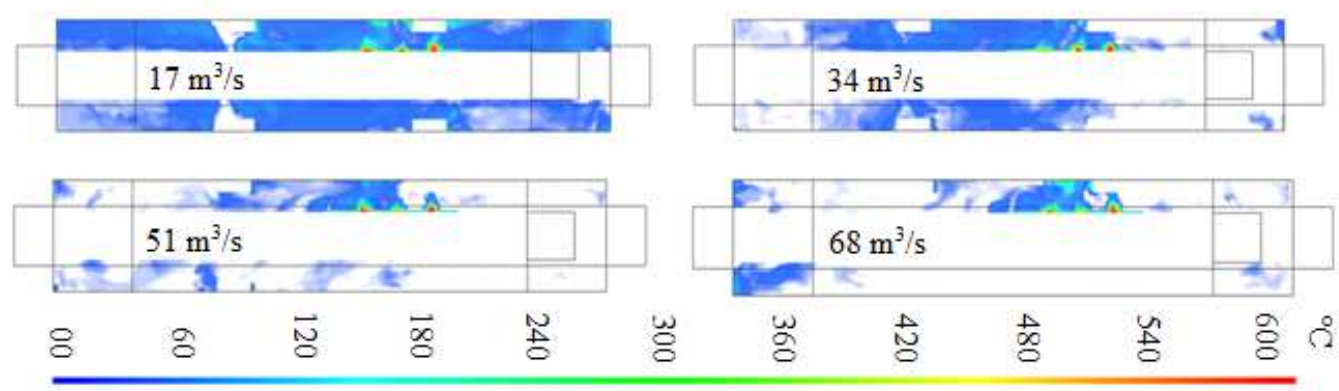

Fig.8. Horizontal cross-section temperature field $1.5 \mathrm{~m}$ above the ground,

(a) mezzanine, (b) platforms

The results in figsures $8(\mathrm{a}, \mathrm{b})$ agree well with those shown in Table 1 . The effect due to the increase of blowing flow rate on smoke behavior is better perceptible. Note that, for large blowing flow rates, security conditions on the mezzanine are critical, while on platforms 
many zones are safe. Such secure areas can serve as temporary refuge for passengers and also allow installing emergency exits as reported by Tsukahara et al. [19]. The zone between the stairways characterized by temperatures that cannot be supported by passengers is the most dangerous. Temperature distributions along the platform, on the side where the train is parked, are drawn based on records of thirteen measurement points, for various tunnels blowing flow rates (Fig. 9a). They show that the central part, between the stairways, is the part that is exposed to the highest temperatures as discussed above. We also remark that the zone of maximum temperature shifts to the left with increasing blowing flow rate, due to unequal gas rates that are set in motion through both stairways (Fig. 9b).
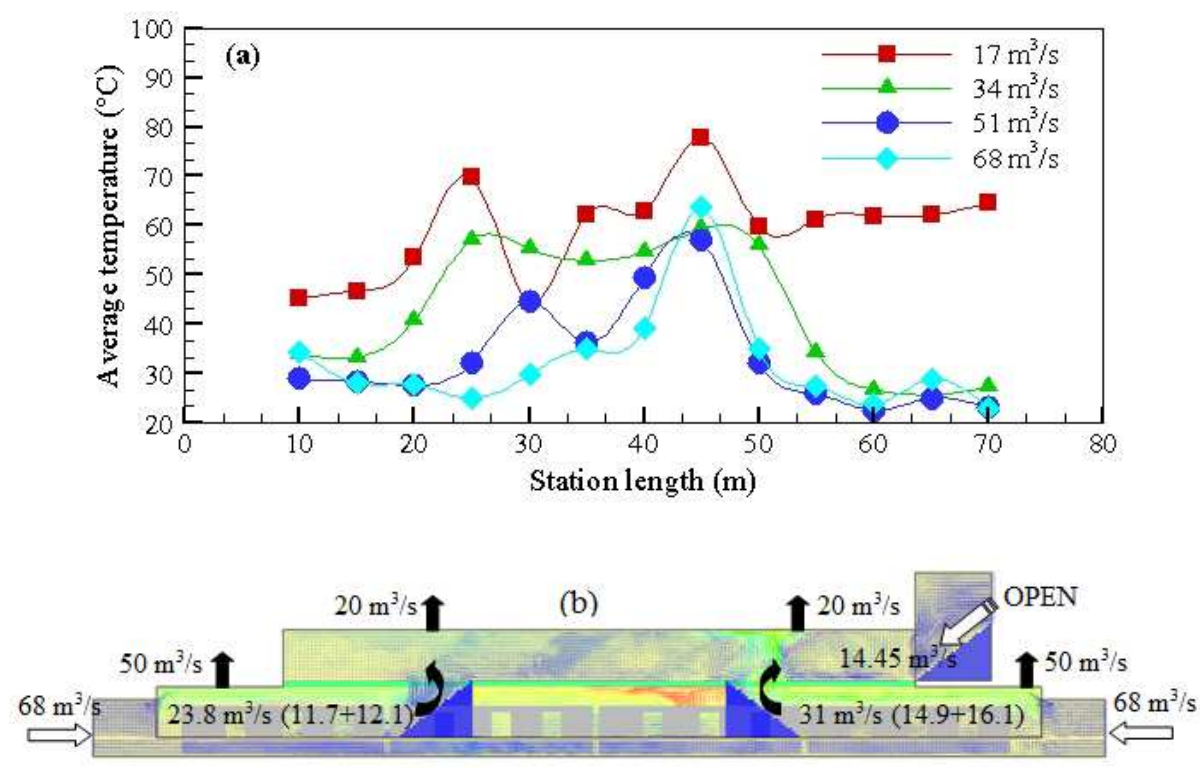

Fig.9. (a) Temperature profiles along the platform for selected blowing rates, (b) Flow rates set in motion in the station for $68 \mathrm{~m}^{3} / \mathrm{s}$ tunnel blowing flow rate case

Although temperature levels in the mezzanine are acceptable for low flow rates, pathways leading to it are unfortunately blocked by toxic smoke at high temperature (Fig. 10); this makes more difficult the evacuation of passengers.

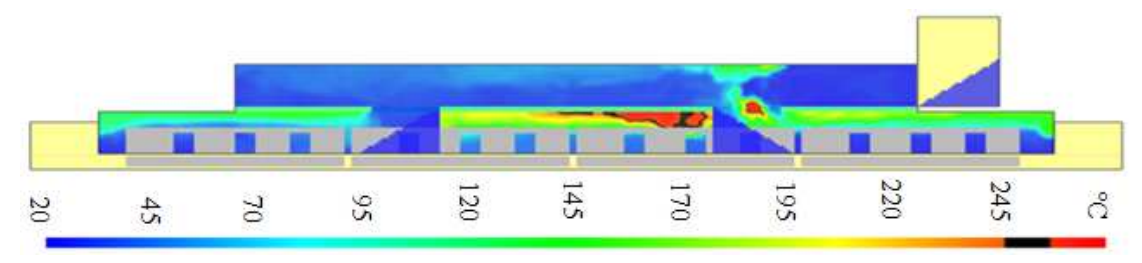

Fig.10. Mezzanine gas temperature field for tunnels low blowing rate case

- Impact of extraction through the mezzanine on the spread of smoke 
To study the effect of extraction flow rate through the vents of the mezzanine, simulations were performed with selected rates $10 \mathrm{~m}^{3} / \mathrm{s}, 20 \mathrm{~m}^{3} / \mathrm{s}, 30 \mathrm{~m}^{3} / \mathrm{s}, 40 \mathrm{~m}^{3} / \mathrm{s}$, and $50 \mathrm{~m}^{3} / \mathrm{s}$. The airflow through each tunnel was set to $34 \mathrm{~m}^{3} / \mathrm{s}(1 \mathrm{~m} / \mathrm{s})$, and to $68 \mathrm{~m}^{3} / \mathrm{s}(2 \mathrm{~m} / \mathrm{s})$. The obtained temperature fields in the horizontal cross-section $1.5 \mathrm{~m}$ above the ground are shown in (Fig. 11). Only values above $40{ }^{\circ} \mathrm{C}$ for the mezzanine and the platforms are shown.

It was found that increasing the rate of extraction contributes significantly to the reduction of temperature in the mezzanine. Indeed, without extraction through the vents at the ceiling, smoke and hot air ascending by the stairways would be trapped and would accumulate; consequently inducing a temperature increase.

(a) Tunnels blowing flow rate $=34 \mathrm{~m}^{3} / \mathrm{s}$

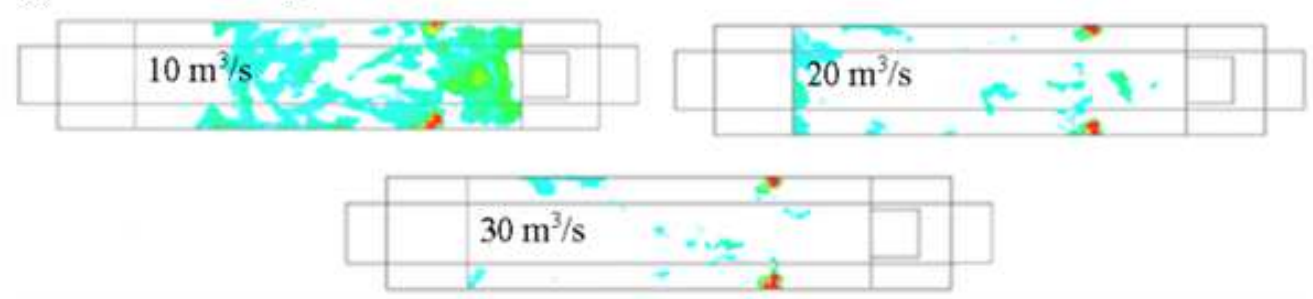

(b) Tunnels blowing flow rate $=68 \mathrm{~m}^{3} / \mathrm{s}$

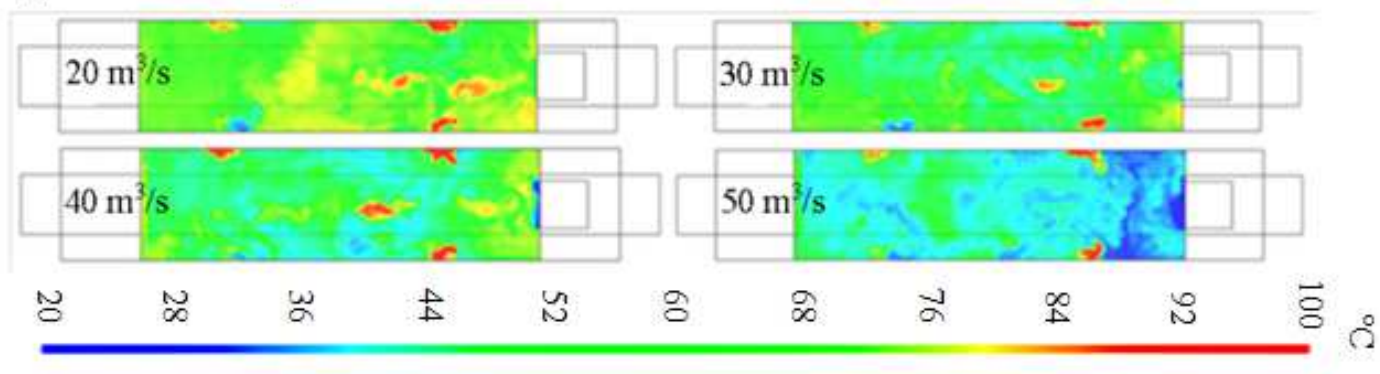

Fig.11. Mezzanine temperature field $1.5 \mathrm{~m}$ from the ground

To ensure a secure area, at a height of $1.5 \mathrm{~m}$ above the ground in the mezzanine, the minimum extraction rate through the vents depends on flow blowing through tunnels. In the first case one finds that, beyond the rate of $20 \mathrm{~m}^{3} / \mathrm{s}$, the temperature distribution is no longer affected by the extraction through the mezzanine (Fig. 11a). This flow rate limit constitutes the minimum required extraction flow. However, in the second case, for flows over $50 \mathrm{~m}^{3} / \mathrm{s}$, temperature distribution is sensitive to the extraction through the mezzanine (Fig. 11b).

In conclusion, it can be noted that blowing through both tunnels allows maintaining a well-stratified smoke layer at the platforms, which is generally a desired result. The stairways are natural evacuation pathways. These latter, which were originally also our concern, were 
found at higher temperature levels when blowing flow rate is increased; Hence, It would be difficult to keep an acceptable level of safety for both mezzanine and platforms.

\subsection{Strategy two: extraction of air smoke mixture through tunnels}

In this configuration, extraction is carried out through both tunnels. The selected extraction flow rates are $17 \mathrm{~m}^{3} / \mathrm{s}(0.5 \mathrm{~m} / \mathrm{s})$ and $68 \mathrm{~m}^{3} / \mathrm{s}(2.0 \mathrm{~m} / \mathrm{s})$. Extraction flow rates of $20 \mathrm{~m}^{3} / \mathrm{s}$ through each vent of the mezzanine and $50 \mathrm{~m}^{3} / \mathrm{s}$ through each vent of the platforms are kept constant. Effect of extraction flow rate through tunnels on smoke spread in the station, and particularly in the mezzanine is examined.

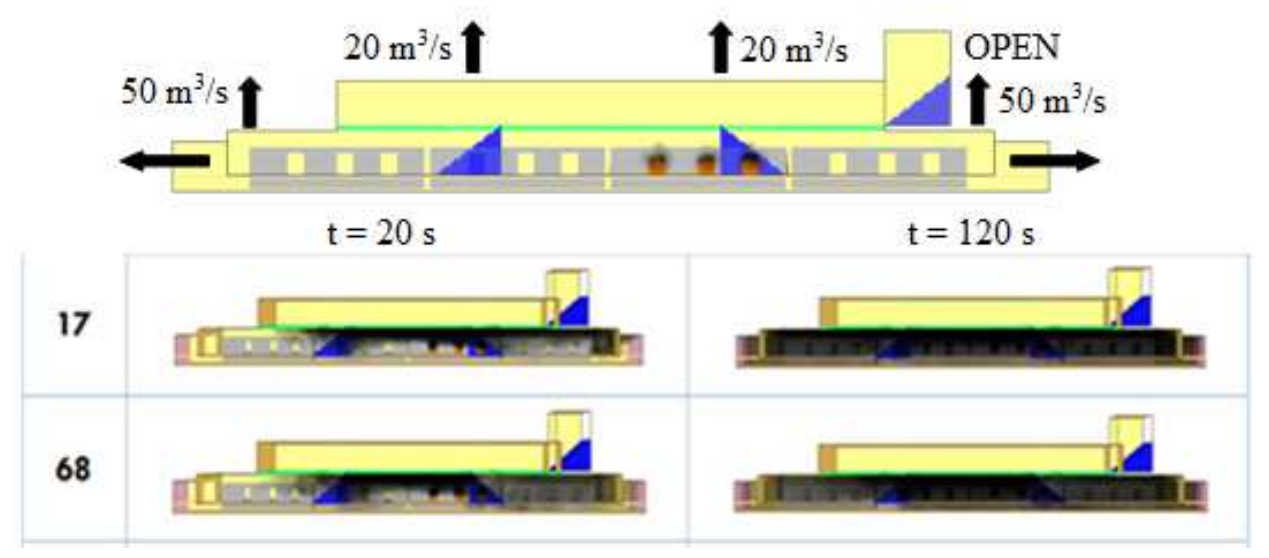

Fig.12. Smoke spread at the station (extraction through tunnels)

The depression on the platforms level created by the extraction involves air currents coming down through stairways. Smoke does not flow upwards to the upper level and consequently, temperature in the mezzanine remains constant and equal to the initial temperature. It can be seen from smoke field results shown in (Fig.12) that smoke, which naturally tends to stratify under the ceiling, is quickly disrupted after 20 seconds. It is affected by the air stream which descends to the platforms through the stairways. We also remark that smoke near the tunnels, is more diluted for higher tunnels flow rate extraction. This is due to mixing with sucked fresh air through stairways. Table 2 illustrates platforms average temperature $1.5 \mathrm{~m}$ height above the ground, maximum temperature, and the percentage of points registering temperatures over $40{ }^{\circ} \mathrm{C}$, for various tunnels extraction flow rates. 
Table 2. Platforms average and maximum temperature

\begin{tabular}{ccccc}
\hline \multicolumn{2}{c}{ Flow rates $\left(\mathrm{m}^{3} / \mathrm{s}\right)$} & \multicolumn{3}{c}{ Temperature $\left({ }^{\circ} \mathrm{C}\right)$} \\
\hline Extraction & Extraction & Average & Max. & $\%$ Temp. \\
(Tunnels) & (Mezz.) & Temp. & Temp. & Platf. $>40{ }^{\circ} \mathrm{C}$ \\
\hline 17 & 20 & 70.49 & 110 & 100 \\
34 & 20 & 67.43 & 105 & 100 \\
51 & 20 & 60.03 & 106 & 92.3 \\
68 & 20 & 56.85 & 117 & 80.8 \\
\hline
\end{tabular}

It can be remarked from Table 2 that the increase of tunnels extraction rate results in a decrease in the average platform temperature. It is worth noting that this latter remains higher than $40{ }^{\circ} \mathrm{C}$. Temperature profiles along platform, where the train is parked are drawn for selected tunnels extraction rates in (Fig. 13). It shows that the central zone, located between stairways, is the critical one. It is exposed to high smoke temperature. The zones on either side of the stairways constitute safer zones.

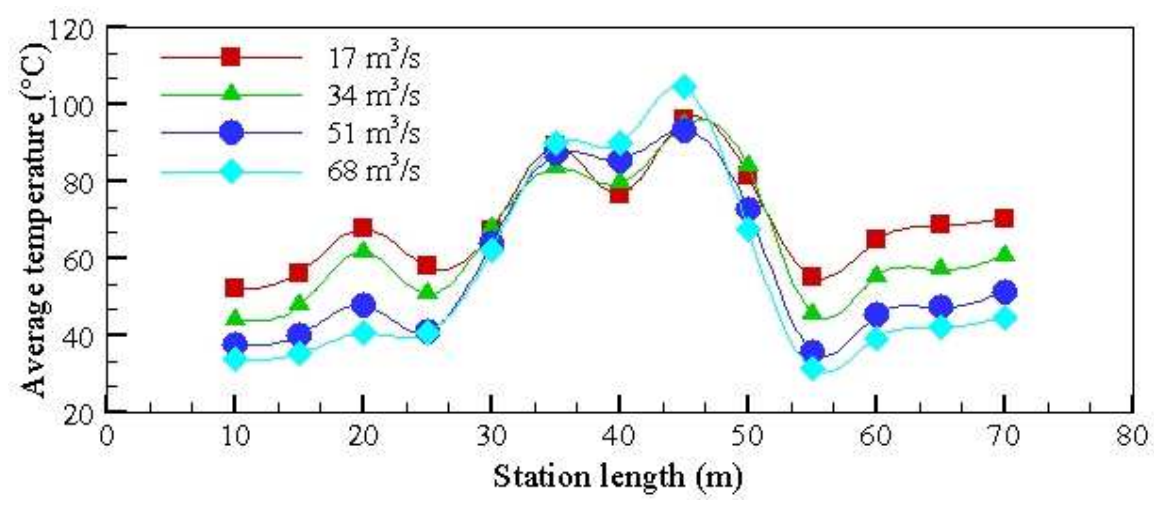

Fig.13. Temperature profiles along platform as a function of selected extraction rates

Figure 13 also depicts that temperature profiles overlap on either side of the stairways. We remark an increase of the maximum temperature with increasing extraction flow rate in the vicinity of stairways. This is due to an excess call of fresh air which prevents smoke extraction from the central zone.

\section{- Effect of extraction through the mezzanine vents}

Mezzanine smoke spread tests were performed for two ceiling vents location. Results showed 
that, there is no significant effect of vents location in the mezzanine on smoke spread and consequently, on temperature level in the station. Only extraction rates could have an impact on temperature fields, as demonstrated for cases where blowing inside the station through tunnels is performed. It has also been shown previously that fumes remain concentrated in the bottom level of the station and fresh air is sucked in through stairways for extraction strategy through tunnels, thus the usefulness of the extraction through vents located at the upper level is questionable. To better verify the ineffectiveness of extraction through vents of the mezzanine, we imposed $34 \mathrm{~m}^{3} / \mathrm{s}$ extraction rate through each tunnel, and examined the effect of the extraction rate through the vents of the mezzanine considering the following rates: 0 $\mathrm{m}^{3} / \mathrm{s}, 10 \mathrm{~m}^{3} / \mathrm{s}, 20 \mathrm{~m}^{3} / \mathrm{s}$, and $30 \mathrm{~m}^{3} / \mathrm{s}$. The results of platform smoke temperature are shown in Table 3. It can be noted that the effect of the extraction flow rate is negligible, and unfortunately against what is desired, the conditions at the platforms slightly deteriorate. Consequently, it is recommended stopping extraction from the mezzanine in case one opts for the strategy of smoke extraction through tunnels. Nevertheless, extraction in the mezzanine can be performed when the fire source is located in the mezzanine.

Table 3. Results on the effect of extraction through the vents of the mezzanine

\begin{tabular}{cclll}
\hline \multicolumn{2}{c}{ Flow rates $\left(\mathrm{m}^{3} / \mathrm{s}\right)$} & \multicolumn{3}{c}{ Temperature $\left({ }^{\circ} \mathrm{C}\right)$} \\
\hline Extraction & Extraction & Average & Max. & $\%$ Platf. \\
(tunnels) & (Mezz.) & Platf. Temp. & Temp. & Temp. $>40^{\circ} \mathrm{C}$ \\
\hline 34 & 0 & 63.05 & 91.31 & 92.31 \\
34 & 10 & 65.56 & 105.26 & 96.15 \\
34 & 20 & 67.43 & 105.05 & 96.15 \\
34 & 30 & 68.81 & 108.69 & 100 \\
\hline
\end{tabular}

\subsection{Strategy three: blowing through one tunnel while extracting through the other}

For this strategy, flow rate through each vent of the mezzanine, and each vent of the platforms are $20 \mathrm{~m}^{3} / \mathrm{s}$ and $50 \mathrm{~m}^{3} / \mathrm{s}$ respectively. Experienced flow rates through tunnels are $34 \mathrm{~m}^{3} / \mathrm{s}, 68$ $\mathrm{m}^{3} / \mathrm{s}, 102 \mathrm{~m}^{3} / \mathrm{s}$ and $136 \mathrm{~m}^{3} / \mathrm{s}$ (positive for one tunnel and negative for the other). The visualizations of smoke spread in (Fig. 14), for these cases show that smoke does not ascend 
to the mezzanine. Air temperature in the mezzanine remains at its initial ambient value. It can also be noted that best results for smoke removal are obtained for high ventilation rate through the farthest tunnel, and high extracting rate through the nearest tunnel of the carriage on fire. However, for low ventilation rate, smoke is well stratified when the ventilation is performed from right to left.

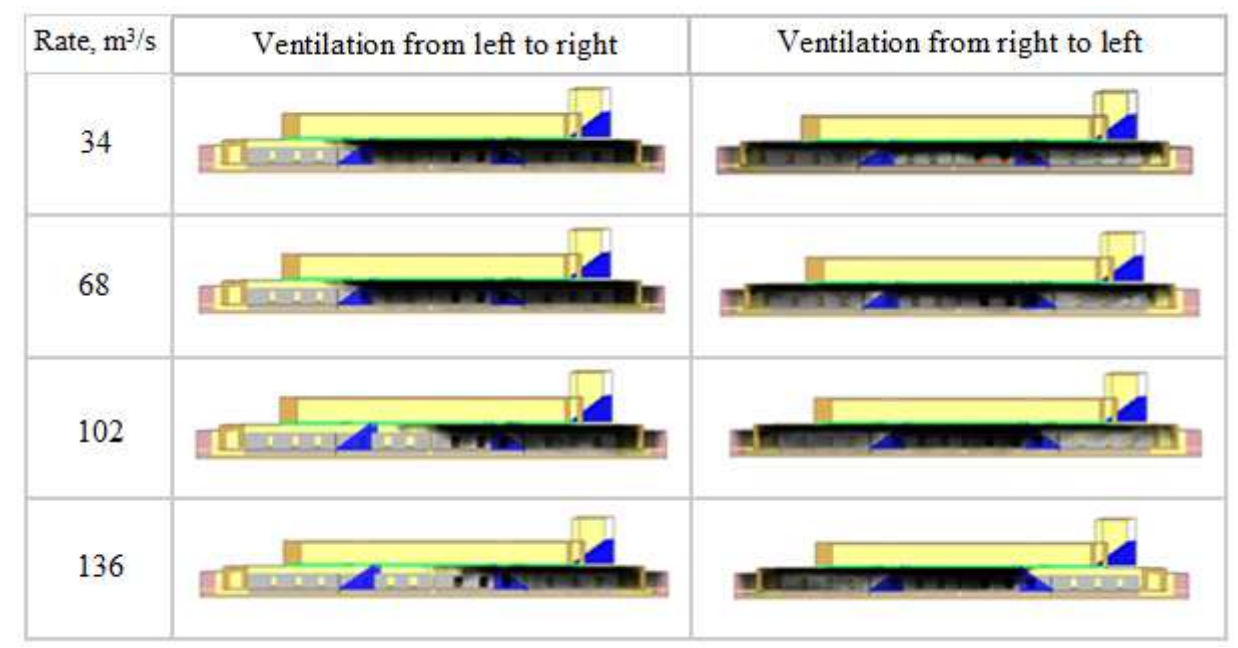

Fig.14. Smoke spread at the station (anti-symmetric ventilation)

Figure 15 shows gas temperature profiles along the platform $1.5 \mathrm{~m}$ height from the ground. For anti-symmetric ventilation from left to right, temperature in the platform decreases significantly with increasing tunnels flow rate. For $136 \mathrm{~m}^{3} / \mathrm{s}$ tunnels flow rate, almost two third of the platform zone is at around $20^{\circ} \mathrm{C}$ (Fig. 15b). The temperature at the right zone has reached $80^{\circ} \mathrm{C}$, which agrees well with the smoky zone (Fig. 15). Note that with this ventilation strategy, we created a secure area on a large part of the platform.

For anti-symmetric ventilation from right to left, platform central part smoke temperature is at unbearable levels (Figs. 15a, b). For $34 \mathrm{~m}^{3} / \mathrm{s}$ tunnels rate, the maximum temperature recorded is about $80{ }^{\circ} \mathrm{C}$; while for $136 \mathrm{~m}^{3} / \mathrm{s}$, the maximum is around $138{ }^{\circ} \mathrm{C}$. Nevertheless, the right platform zone is a clear smoke area with a quite low temperature, around $20^{\circ} \mathrm{C}$ (Fig. 15). 

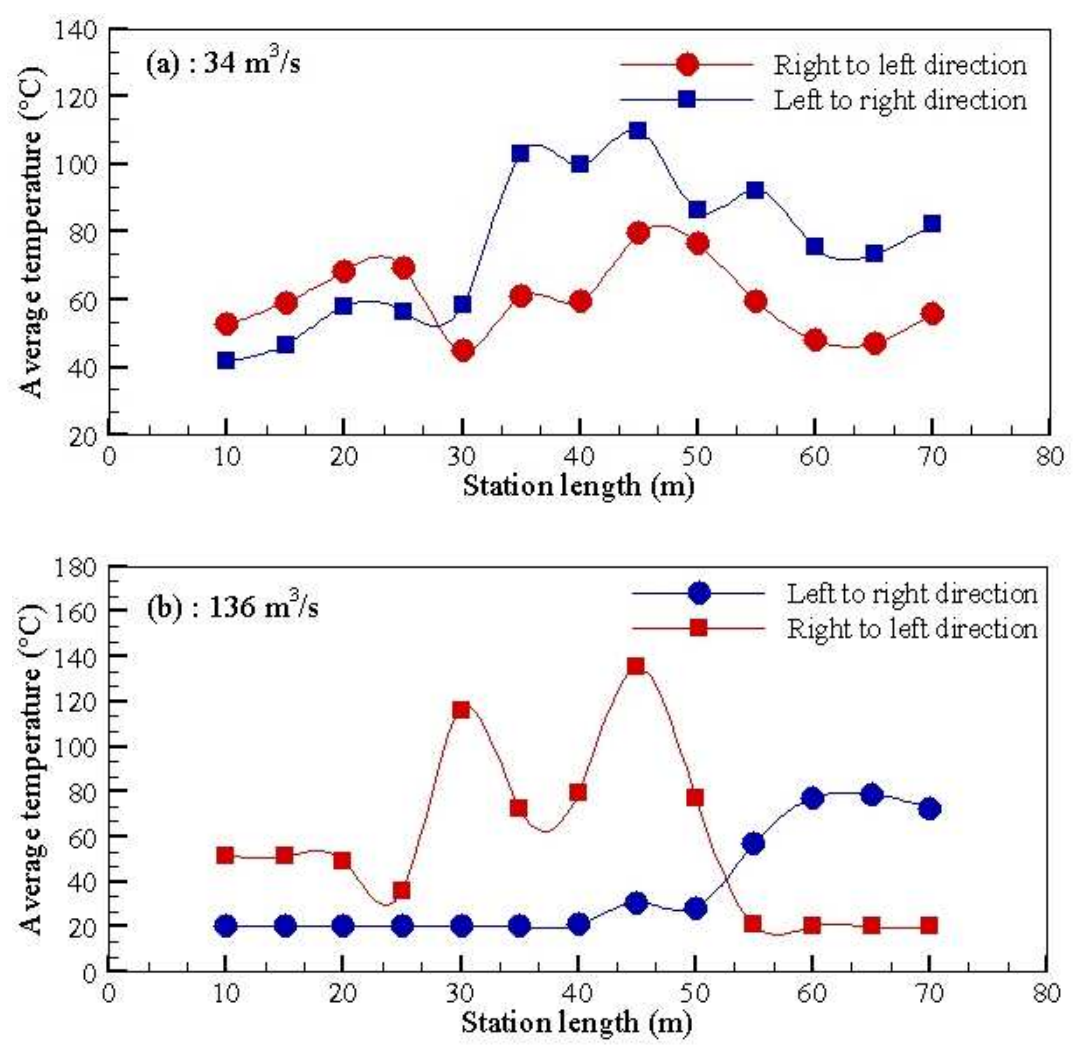

Fig.15. Temperature profile along the platform for anti-symmetric ventilation

The result which depicts an increase in temperature when the ventilation is increased can be explained by the fact that when applying the strategy with an anti-symmetric high flow rate, a competition between the various flow rates (air blowing and smoke extraction) settles. The tunnel airflow rate has the tendency to prevail. It can either increase or decrease the temperature depending on the location of the source fire and the direction of the ventilation. For the ventilation from right to left, smoke spreads vertically under the pressure effect generated by the right tunnel airflow. The gases are therefore, stretched and the hottest smoke particles climb up swiftly, which induces an elevation of temperature. It may also be remarked that this temperature increase happens in the vicinity of the center line of the source at $1.5 \mathrm{~m}$ above the ground. It can be concluded that for low ventilation rates (flow rates less than 50 $\mathrm{m}^{3} / \mathrm{s}$ ), anti-symmetric strategy, which operates with blowing through the tunnel closest to the carriage on fire and extraction through the farthest tunnel, works better. Moreover, for high flow rates anti-symmetric strategy (flow rates higher than $50 \mathrm{~m}^{3} / \mathrm{s}$ ), extracting through the nearest tunnel to the carriage on fire and blowing through the farthest, gives better results. 
Smoke is sucked out of the zone between the stairs, and therefore the evacuation can be safer.

\subsection{Comparison between selected strategies}

Table 4 summarizes relevant results for three evacuation strategies with optimized flow rates of $34 \mathrm{~m}^{3} / \mathrm{s}$ through each tunnel for strategy one, $68 \mathrm{~m}^{3} / \mathrm{s}$ extraction rate through each tunnel for strategy two, and $136 \mathrm{~m}^{3} / \mathrm{s}$ for left to right anti-symmetric strategy three.

Flow rate through each vent of the mezzanine and each vent of the platforms are $20 \mathrm{~m}^{3} / \mathrm{s}$ and $50 \mathrm{~m}^{3} / \mathrm{s}$ respectively for all strategies. Table 4 illustrates platforms and mezzanine average and maximum temperatures, also maximum and minimum temperatures at four points located at relevant positions in the stairways. The temperature at the selected points in the stairways indicates the dangerousness of the unique ways of communication between both levels.

Table 4. Temperature comparison for selected strategies

\begin{tabular}{lllllll}
\hline \multirow{2}{*}{ Strategy } & \multicolumn{2}{c}{ Platfs. Temp. $\left({ }^{\circ} \mathrm{C}\right)$} & \multicolumn{2}{c}{ Mezz. Temp. $\left({ }^{\circ} \mathrm{C}\right)$} & \multicolumn{2}{c}{ Stairs Temp. $\left({ }^{\circ} \mathrm{C}\right)$} \\
\cline { 2 - 7 } & Average & Max. & Average & Max. & Max. & Min. \\
\hline$(1)$ & 41.57 & 59.32 & 32.28 & 39.99 & 188 & 36 \\
$(2)$ & 56.85 & 117 & 20 & 20 & 20 & 20 \\
$(3)$ & 42.43 & 83 & 20 & 20 & 20 & 20 \\
\hline
\end{tabular}

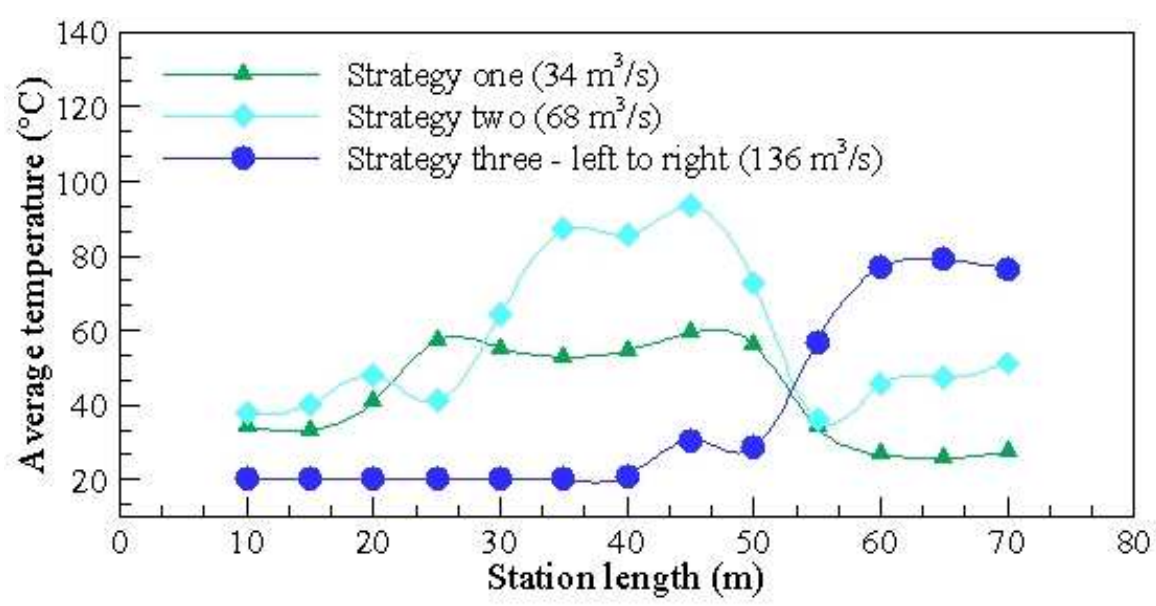

Fig.16. Temperature distribution along platforms, for selected strategies with optimized flow rates

From Figure 16 and Table 4, it is worth noting that strategy (2) can be considered, when secure zones on either side are aimed; although the platform temperature between stairways exceeds $100{ }^{\circ} \mathrm{C}$. For strategy (1), the temperature on either side of the stairways at the lower 
level of the station is rather low, but at the central area and in the vicinity of left stairways, it is quite high. We note that, blowing through tunnels has the advantage of keeping smoke stratified at the platform level, which is a relevant result. Thus, installing smoke curtains at the upper part of the stairs can be considered. Strategy (3) remains the best smoke evacuation strategy. Indeed, we note that with such ventilation strategy, temperature in the mezzanine is at ambient temperature; stairways are not being blocked by smoke and gases at high temperature, and the hot zone is located on the right side platforms level of the station (Fig. 16). However this strategy has a major disadvantage. It could endanger passengers blocked in the right tunnel.

\subsection{Test with vertical smoke curtains}

It was shown previously that, tunnels blowing strategy (1) has the advantage of promoting smoke stratification beneath the ceiling. Tunnels extraction strategy (2) and anti-symmetric ventilation strategy (3) result in situations with moderate temperature, but platforms volume is filled with quite dense smoke. The position at the ceiling of the communication routes, between both levels conducts to their quick blockage by hot and toxic smoke.

The arrangement which consists of installing smoke barriers to prevent stairways to be invaded by stratified and confined smoke is implemented. A $1.25 \mathrm{~m}$ height smoke curtains, placed under the ceiling separating both levels are used (Fig. 17).

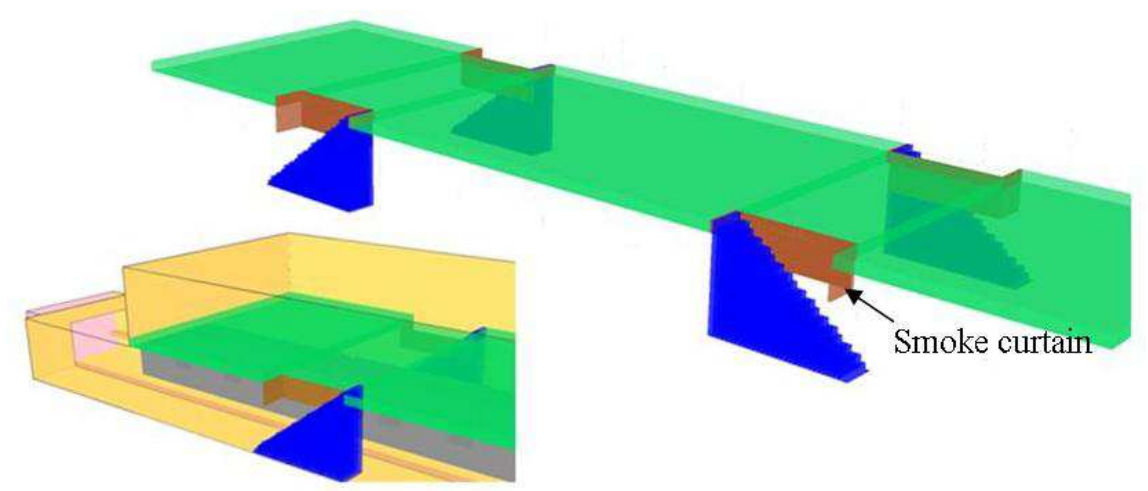

Fig.17. Station equipped with smoke curtains

Results depicted in (Fig. 18) show the effect of these curtains on the smoke spread in the station. We remark that, in the presence of curtains, smoke is prevented from rising to the mezzanine at moderate tunnels blowing rate of $34 \mathrm{~m}^{3} / \mathrm{s}$. It is worth noting that smoke opacity 
is also much lower for high tunnels blowing rate of $68 \mathrm{~m}^{3} / \mathrm{s}$.

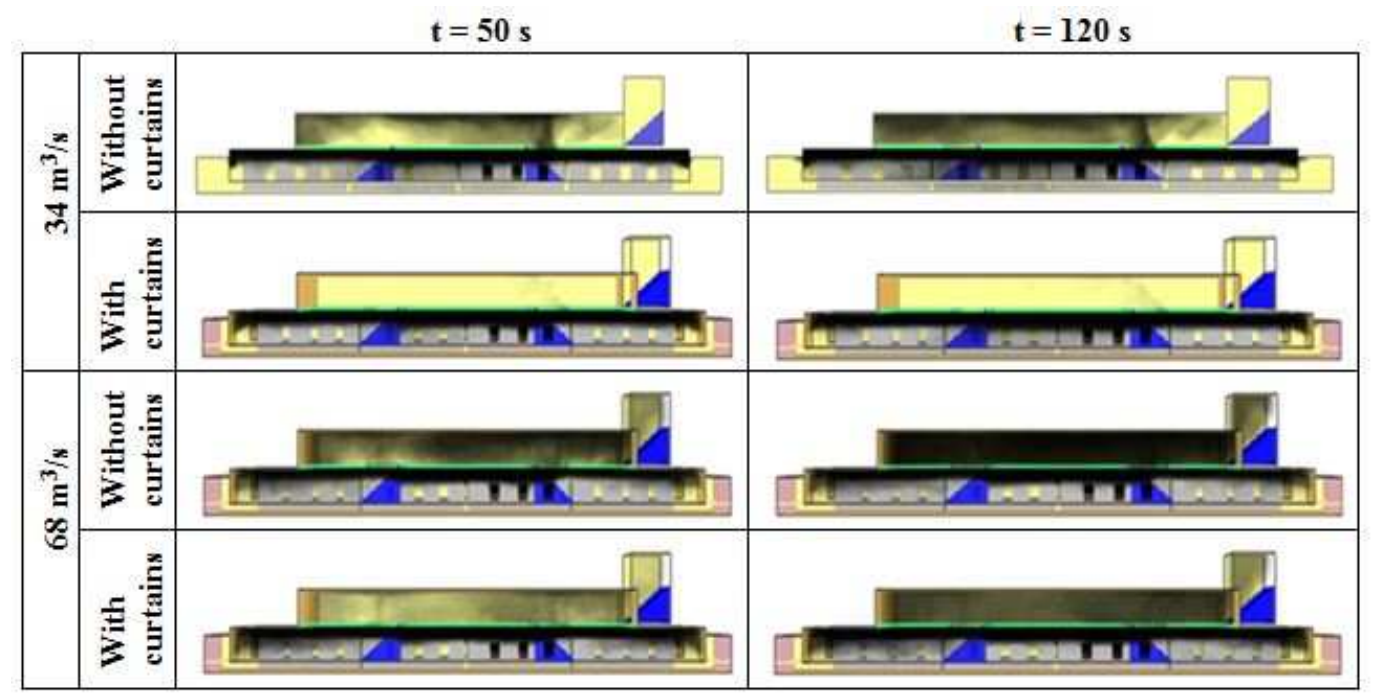

Fig.18. Station smoke spread (with and without curtains), strategy (1)

Results in Table 5 show for both experienced cases, that average and maximum mezzanine temperature have decreased. It can be noted that, for low tunnels blowing rate, average platforms temperature has also decreased, while maximum temperature increases. This is due to the fact that, smoke curtains prevented fumes going up, and consequently accumulate; thus resulting in temperature increase. For high tunnels blowing rate, increase in average and maximum temperatures is recorded. Results in Table 5 indicates also that temperature at the stairways center has decreased considerably when smoke curtains were introduced for both selected tunnel blowing flow rates.

Table 5. Temperature at the mezzanine and platforms, with and without curtains

\begin{tabular}{llllllllll} 
& $\begin{array}{l}\text { Rate } \\
\end{array}$ & \multicolumn{5}{c}{ Temperature $\left({ }^{\circ} \mathrm{C}\right)$} & & Stairs \\
\cline { 2 - 6 } & $\left(\mathrm{m}^{3} / \mathrm{s}\right)$ & Average & \multicolumn{3}{c}{ Maximum } & \% Temp. $>40^{\circ} \mathrm{C}$ & Max. \\
\cline { 2 - 7 } & Tunnels & Mezz. & Platf. & Mezz. & Platf. & Mezz. & Platf. & Temp. \\
\hline No curtains & 34 & 32.28 & 41.57 & 39.99 & 59.32 & 0 & 46.15 & 131 \\
Curtains & 34 & 20.9 & 36.95 & 25.39 & 69.82 & 0 & 19.23 & 38.6 \\
\hline \hline No curtains & 68 & 63.45 & 34.51 & 79.97 & 63.44 & 100 & 3.85 & 130.6 \\
Curtains & 68 & 38.26 & 39.42 & 44.55 & 76.67 & 26.92 & 11.54 & 55.8 \\
\hline
\end{tabular}


Mezzanine temperature rise, for tunnels blowing flow rates of $34 \mathrm{~m}^{3} / \mathrm{s}$ and $68 \mathrm{~m}^{3} / \mathrm{s}$ is drawn in (Fig. 19). Results with smoke curtains are presented. It can be observed that temperature is significantly lowered when curtains are introduced for low tunnel blowing flow rate. Moreover, case with high tunnel blowing flow rate and smoke curtains, illustrates more available time for the evacuation operation. The mezzanine average temperature remains below $40^{\circ} \mathrm{C}$ for more than $300 \mathrm{~s}(5 \mathrm{mn})$. Indeed, we note that the time required to reach $30^{\circ}$ $\mathrm{C}$ in the presence of curtains is doubled compared to that without curtains. To reach the reference temperature of $40^{\circ} \mathrm{C}$, this time can be multiplied by a factor of 6 .
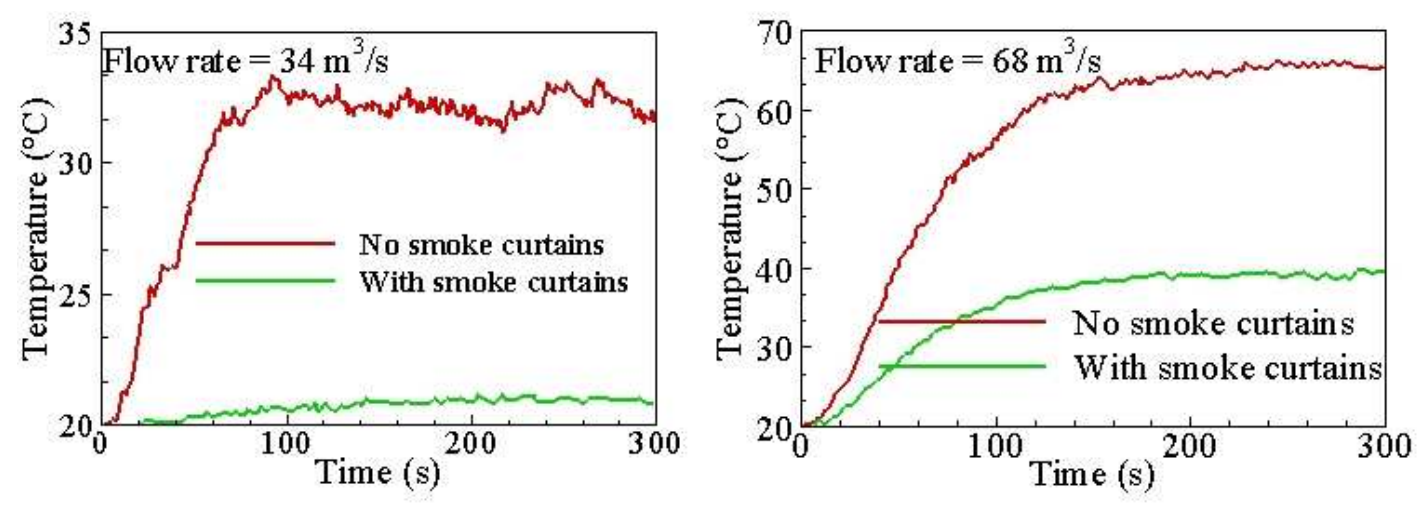

Fig.19. Average temperature rise in the mezzanine, with and without curtains

\section{CONCLUDING REMARKS}

The aim of this study was to put forward a two level underground station smoke control. Numerical simulation was employed to evaluate the effectiveness of conventional smoke removal regulation and assess selected smoke control strategies. The relevant parameters used for analysis are smoke propagation fields and smoke temperature distributions.

Selected smoke removal strategies have been examined. They consisted mainly of tunnels blowing, tunnels extraction, and tunnels anti-symmetric ventilation. Each of these strategies showed advantages and drawbacks. The discussion of the results led to the following relevant conclusions:

- The study has highlighted the deficiency of conventional smoke control regulation, applied for multi-level underground station, since both the mezzanine and the platforms cannot be considered secured areas. 
- Blowing through tunnels promotes containment and stratification of the smoke layer under the ceiling of the platforms, but users intuitive escape ways (stairs) are blocked, unless smoke curtains are implemented.

- Extraction through tunnels has the advantage of preventing the rise of smoke and heat to the upper level. At the level of platforms, extractions through tunnels and vents induce strong air current down the stairs which affect the natural smoke stratification.

- The anti-symmetric ventilation, i.e. blowing through one tunnel while extracting through the other, is appropriate in cases where the fire is in the vicinity of one of the tunnels. In such cases, smoke is discharged via the nearest tunnel to the fire; consequently the station is secured on the other side. However this strategy has a major disadvantage. It could endanger passengers blocked in the tunnel.

- Finally, this work highlighted the irrefutable impact of the curtains on the smoke spread, the protection of the mezzanine and the station in general.

- These smoke curtains maintain the smoke outside the space they delimit under the ceiling, which allows the protection of the communication pathways between both levels; thus delaying if not preventing the smoke rising to the mezzanine.

\section{REFERENCES}

[1] Chen, F., Guo, S.C., Chuay, H.Y., and Chien, S.W., Smoke control of fire in subway station: Theoretical and computational fluid dynamics Journal, 2003, 16, 349-368.

[2] Park, W. H., Kim, D. H., Chang H. C., Numerical predictions of smoke movement in subway station under ventilation, Tunnelling and Underground Space Technology, 2006, 21, 304.

[3] Li, J.S.M., Chow, W.K., Numerical studies on performance evaluation of tunnel ventilation safety systems, Tunnelling and Underground Space Technology, 2003, 18, $435-452$.

[4] Rie, D.H., Hwang, M.W., Kim, S.J., Yoon, S. W., Ko, J. W., Kim, H.Y., A Study of optimal vent mode for the smoke control of subway station fire, Tunnelling and Underground Space Technology, 2006, 21, 300-306. 
[5] Yuan, F. D., You, S. J., CFD Simulation and optimization of the ventilation for subway side-platform: Tunnelling and Underground Space Technology, 2007, 22, 474-482.

[6] Hua, L.H., Huo, R., Chow, W.K., Studies on buoyancy-driven back-layering flow in tunnel fires: Experimental Thermal and Fluid Science, 2008, 32, 1468-1483.

[7] Roh, J.S., Ryou, H.S., Park, W.H., Jang, Y.J., CFD simulation and assessment of life safety in a subway train fire: Tunnelling and Underground Space Technology, 2009, 24, 447-453.

[8] Zhong, J. Ji. W., Li, K.Y., Shen, X.B., Zhang, Y., Huo, R., A simplified calculation method on maximum smoke temperature under the ceiling in subway station fires, Tunnelling and Underground Space Technology, 2011, 26, 490-496.

[9] Tsukahara, M., Koshiba, Y., Ohtani, H., Effectiveness of downward evacuation in a large-scale subway fire using Fire Dynamics Simulator: Tunnelling and Underground Space Technology, 2011, 26, 573-581.

[10] Arrêté du 20 février 1983 portant approbation des règles de sécurité et des modalités de contrôle applicables aux locaux accessibles au public (Journal officiel - NC du 23 avril 1983). [11] Gil-Lopez, T., Galvez-Huerta, M. A., Castejon-Navas, J., Gomez-Garcia, V., A first approach to the problem of settling the ventilation rate that minimizes the predicted percentage of dissatisfied, application to a clean room: Adv. Sci. Lett., 2013, 19, 2823-30.

[12] McGrattan, K., McDermott, R., Hostikka, S., Floyd, J., Fire Dynamics Simulator User's Guide: National Institute of Standards and Technology, 2010a.

[13] McGrattan, K., Hostikka, S., Floyd, J., Baum, H., Rehm, R., Mell, W., McDermott, R., Fire Dynamics Simulator Technical Reference Guide: National Institute of Standards and Technology, 2010b.

[14] Hu, L.H., Huo, R., Peng. W., Chow, W. K., Yang, R. X., On the maximum smoke temperature under ceiling in tunnel fires.Tunnelling and Underground Space Technology, 2006, 21, 650-655.

[15] Cochard, S., Validation of the freeware Fire Dynamics Simulator Version 2.0 for simulating tunnel fires, Tunnel Management International Journal, 2003, 6(4): 32-37.

[16] Hu, L. H., Huo, R., Wang, H. B., Yang, R. X., Experimental and numerical studies on longitudinal smoke temperature distribution upstream and downstream from the fire in a road 
tunnel. Journal of Fire Sciences, 2007b, 25: 23-43.

[17] Wen, J. X., Kang, K., Donchev, T., Karwatzki, J. M., Validation of FDS for the prediction of medium-scale pool fires, Fire Safety Journal, 2007, 42, 127-138.

[18] Wu, Y., Li, A., Ma, J., Gao, R., Hu, J., Xiao, B., and Zhang, P., Numerical studies on smoke natural filling in an underground passage with validation by reduced-scale experiments, Nature Environment and Pollution Technology, 2013, 12(1), 35-42.

\section{How to cite this article:}

Benkoussas B, Djedjig R, and Vauquelin O. Numerical assessment of conventional regulation effectiveness for smoke removal from a two level underground station. J. Fundam. Appl. Sci., 2016, 8(2), 401-425. 